\title{
Delayed-enhancement cardiovascular magnetic resonance identifies fibrous tissue in children after surgery for congenital heart disease
}

\author{
Matthew A. Harris, MD, ${ }^{a}$ Tiffanie R. Johnson, MD, ${ }^{\mathrm{b}}$ Paul M. Weinberg, MD, ${ }^{\text {a }}$ and Mark A. Fogel, $\mathrm{MD}^{\mathrm{a}}$
}

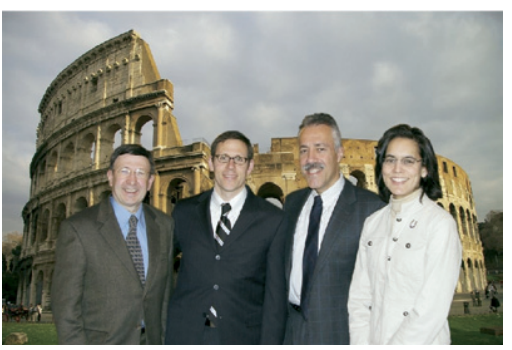

Drs Weinberg, Harris, Fogel, and Johnson (left to right)

$\bigoplus$ Supplemental material is available online.
From the Department of Pediatrics, Division of Cardiology, The Children's Hospital of Philadelphia ${ }^{\text {a }}$; and the Department of Pediatrics, Section of Pediatric Cardiology, J.W. Riley Hospital for Children, ${ }^{\mathrm{b}}$ Philadelphia, Pa.

Received for publication July 31, 2006; revisions received Oct 4, 2006; accepted for publication Oct 16, 2006.

Address for reprints: Matthew Harris, MD, Assistant Professor of Pediatrics and Radiology, Divisions of Cardiology and Cardiac MRI, The Children's Hospital of Philadelphia and the University of Pennsylvania, Office Suite 2205-Main Building, Philadelphia, PA 19103 (E-mail: harrismat@email.chop. edu).

J Thorac Cardiovasc Surg 2007;133:676-81

$0022-5223 / \$ 32.00$

Copyright () 2007 by The American Association for Thoracic Surgery

doi:10.1016/j.jtcvs.2006.10.057
Objectives: To determine whether delayed-enhancement magnetic resonance imaging can identify fibrous tissue associated with patch reconstructions in postoperative patients with congenital heart disease. Additionally, to determine whether fibrous structures not directly related to the surgical reconstruction exhibited delayed enhancement.

Methods: Seventy-three patients underwent magnetic resonance imaging. Studies were retrospectively reviewed for the presence of delayed enhancement along the ventricular outflow tracts, cardiac valves, and where available, the ascending aorta. Three groups were identified. Group A patients $(n=34)$ underwent right ventricular outflow tract reconstruction and ventricular septal defect patch closure. Group B patients $(n=33)$ had never undergone cardiac surgery. Group C patients $(n=6)$ had functional single ventricle and underwent Norwood reconstruction.

Results: In group A, 31 of 34 patients had delayed enhancement of the right ventricular outflow tract, and 14 of 34 had delayed enhancement of the ventricular septal defect patch $(P<.001)$. In group B $(\mathrm{n}=33), 1$ patient with arrhythmogenic right ventricular dysplasia had delayed enhancement limited to the right ventricular outflow tract. The remainder had no delayed enhancement of either outflow tract. Delayed enhancement of the aortic valve and ascending aorta was observed in 13 of $34(P=.002)$ and 10 of $26(P=.05)$ group A patients, respectively, compared with 2 of 33 and 3 of 24 group B patients. In group C, delayed enhancement of the Norwood reconstruction was observed in 5 of 6 patients $(P=.002)$.

Conclusions: Delayed-enhancement imaging detects fibrous tissue along regions of reconstruction in patients who have had surgery for congenital heart disease. Furthermore, delayed-enhancement imaging detects fibrous tissue in regions not directly related to the reconstructive surgery, including cardiac valves and the wall of the ascending aorta.

$\mathrm{P}$ atients with congenital heart defects such as tetralogy of Fallot (TOF) may require surgical intervention involving reconstruction of the right ventricular outflow tract (RVOT) and patch closure of a ventricular septal defect (VSD). Reconstruction of the RVOT is typically performed with cryopreserved homograft tissue as a transannular patch or a valved conduit. ${ }^{1,2}$ VSD patches are most commonly composed of artificial materials such as polytetrafluoroethylene or Dacron. $^{2,3}$ Histologic evidence of fibrous tissue formation has been observed on the surface of homograft and artificial patch material in animal models ${ }^{4,5}$ and humans. ${ }^{6,7}$

Delayed-enhancement (DE) magnetic resonance (MR) imaging can identify myocardial fibrosis. ${ }^{8-11} \mathrm{DE}$ occurs after intravenous administration of a gadolinium chelate, which primarily remains in the interstitial space. The proposed mechanisms involve delayed contrast washout and an increased volume of distribution present in fibrous tissue. ${ }^{12-14}$ 


$$
\begin{aligned}
& \text { Abbreviations and Acronyms } \\
& \begin{aligned}
\text { DE } & =\text { delayed enhancement } \\
\text { FLASH } & =\text { fast low-angle shot } \\
\text { MR } & =\text { magnetic resonance } \\
\text { RVOT } & =\text { right ventricular outflow tract } \\
\text { SSFP } & =\text { steady-state free precession } \\
\text { TOF } & =\text { tetralogy of Fallot } \\
\text { VSD } & =\text { ventricular septal defect }
\end{aligned}
\end{aligned}
$$

We hypothesized that DE should occur in regions directly associated with the surgical reconstruction where fibrous tissue formation occurs. Recently, DE of the RVOT and in the region of VSD repair was reported in adults with TOF. ${ }^{15,16}$ Our study differs in that it specifically investigated the pediatric population, in whom fibrous tissue may not have had the time to form. In addition, fibrous tissue formation in children may affect the surgical reconstruction differently than in adults, because the patients and their hearts continue to grow. Moreover, recent studies have shown that fibrous tissue is found within the aortic sinuses and the wall of the ascending aorta in patients with TOF, providing a possible mechanism for TOF aortopathy. ${ }^{17}$ Therefore, we expanded our DE MR study to determine whether fibrous tissue could be identified in regions not directly involved in the reconstructive surgical repair, such as in heart valves and within the wall of the ascending aorta. Finally, in this study, we confirmed our findings using a control population of patients who had never undergone cardiovascular surgery.

\section{Materials and Methods Patient Population}

We conducted a retrospective review of all pediatric DE MR studies performed at The Children's Hospital of Philadelphia between October 2003 and August 2005. Inclusion criteria required patients to be under age 21 years and to have a DE MR study covering the ventricular outflow tracts. All included studies were satisfactory for interpretation without significant artifact. Two studies were excluded owing to poor image quality. Three groups were identified. Group A patients $(n=34)$ had conotruncal anomalies and underwent both reconstruction of the RVOT and patch closure of a VSD. The mean age at the time of the patients' most recent surgical reconstruction was $1.6 \pm 2.7$ years. The time between surgery and the MR study was $8.9 \pm 5.5$ years (Table E1). Group B patients $(\mathrm{n}=33)$ had never undergone cardiovascular surgery. Fifteen of these patients had congenital heart disease, 7 had acquired heart disease, and 11 had no evidence of cardiovascular disease confirmed by cardiac MR (Table E2). Group C patients $(n=6)$ had functional single ventricle and underwent Norwood aortic reconstruction with homograft patch (Table E3). All remaining MR studies that did not fall into one of these three categories were excluded. Group A ages ranged from 10 months to 20 years (mean $10.6 \pm 5.2$ years), group $\mathrm{B}$ ages ranged from 10 days to 20 years (mean $11.5 \pm 6.7$ years), and group $C$ patient ages ranged from 2 to 18 years (mean $7.9 \pm 7.4$ years). The local institutional review board approved this retrospective study.

\section{Cardiovascular MR}

Studies were performed on 1.5-T Siemens Sonata or Avanto systems (Siemens Medical Solutions, Malvern, Pa). Group A patients' assessments routinely included evaluation of the RVOT and pulmonary artery architecture, as well as quantification of right ventricular volume, function, and pulmonary regurgitation. Group B patients presented most commonly for assessment of ventricular function. Studies were retrospectively reviewed for the presence of delayed gadolinium enhancement in the region of the ventricular outflow tracts, valve leaflets, and the ascending aorta.

Patients under 7 years of age were typically sedated for the MR study with pentobarbital, and midazolam, except for infants under age 1 , who received chloral hydrate. No complications were observed.

Approximately 10 minutes after the administration of gadopentetate dimeglumine, $(0.4 \mathrm{mmol} / \mathrm{kg})$, and with the appropriate inversion time to achieve myocardial nulling, DE imaging was executed in the same long- and short-axis planes that were used for cine imaging. Comparison of the cine and DE images distinguished DE from other potential causes of bright signal, such as pericardial fat or fluid. DE studies consisted of steady-state free precession (SSFP) or fast low-angle shot (FLASH) inversion recovery sequence with and without phase-sensitive inversion recovery. Typical SSFP parameters were repetition time $10 \%$ of R-R interval, echo time $1.3 \mathrm{~ms}$, inversion time $300 \mathrm{~ms}$, flip angle $45^{\circ}$, segments 65 , and voxel size $1.8 \times 1.3 \times 8.0 \mathrm{~mm}$. Typical FLASH parameters were repetition time $10 \%$ of R-R interval, echo time $4.4 \mathrm{~ms}$, inversion time $260 \mathrm{~ms}$, flip angle $30^{\circ}$, segments 25 , and voxel size $1.7 \times 1.3 \times 8.0 \mathrm{~mm}$. Infant studies included single-shot acquisition, two averages, and thinner slices $(5.0-6.0 \mathrm{~mm})$. Group A studies were reviewed for the presence or absence of DE of the RVOT patch/conduit, VSD patch, valve leaflets, and where available, the ascending aorta. Group B studies served as controls. Group C studies were reviewed for DE of the aortic reconstruction.

\section{Statistical Analysis}

Data are expressed as mean and SD range as appropriate. The Fisher exact test was performed as appropriate.

\section{Results \\ RVOT and VSD Patch}

In group A $(\mathrm{n}=34)$, DE of the RVOT reconstruction occurred in $31(91 \%)$ patients compared with $1(3.0 \%)$ of 33 patients without surgery (group B) $(P<.001)$ (Figure 1 ; Table 4). One patient, with the diagnosis of double-chambered right ventricle, underwent subpulmonary resection and VSD closure without homograft patching and still had $\mathrm{DE}$ in the region of the RVOT. The only group B patient to exhibit DE of the RVOT had arrythmogenic right ventricular dysplasia.

In group A $(\mathrm{n}=34), \mathrm{DE}$ of the VSD patch occurred in $14(41 \%)$ of 34 patients, compared with 0 of 33 group B 

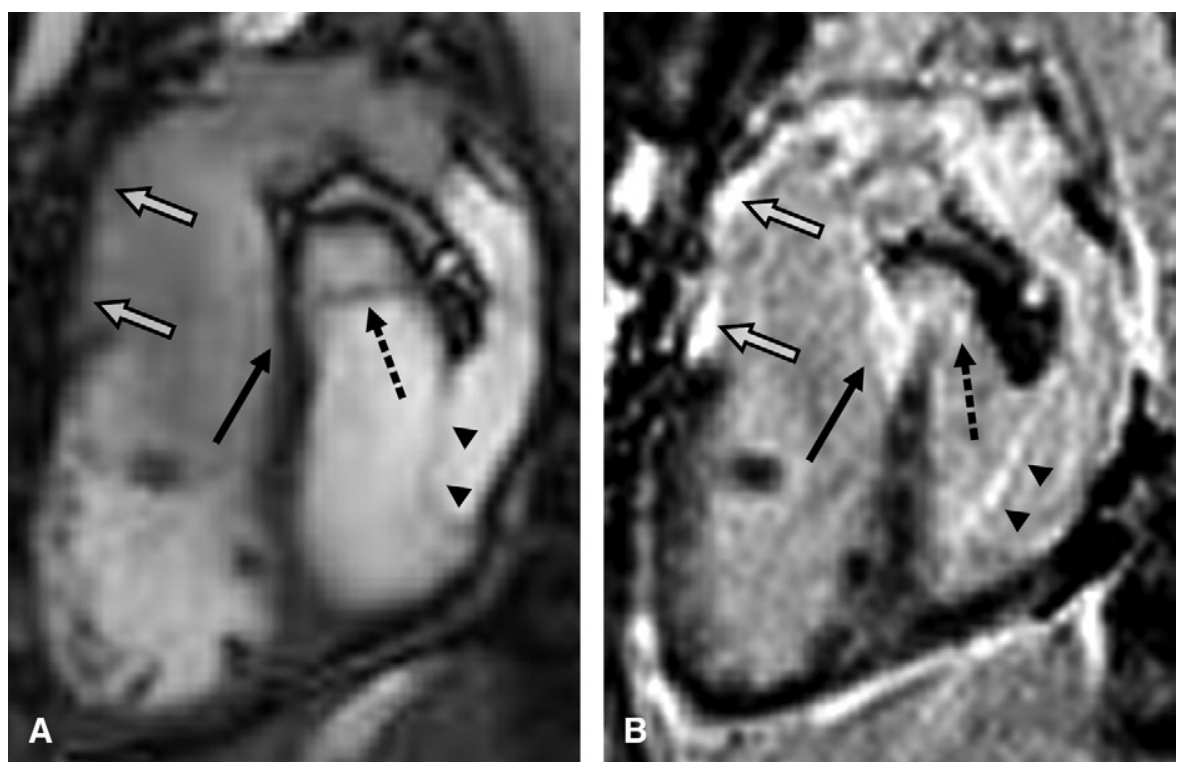

Figure 1. A 3-year-old girl after repair of truncus arteriosus at 1 week of age. A, Right ventricular outflow tract view, steady-state free precession (SSFP) cine image, and the corresponding SSFP phase sensitive inversion recovery image (B). Note the prominent delayed enhancement along the anterior wall of the right ventricular-pulmonary artery conduit (open arrows) and the ventricular septal defect patch (long solid arrow). Also, note delayed enhancement of the truncal (dashed arrow) and mitral valves (arrowheads).

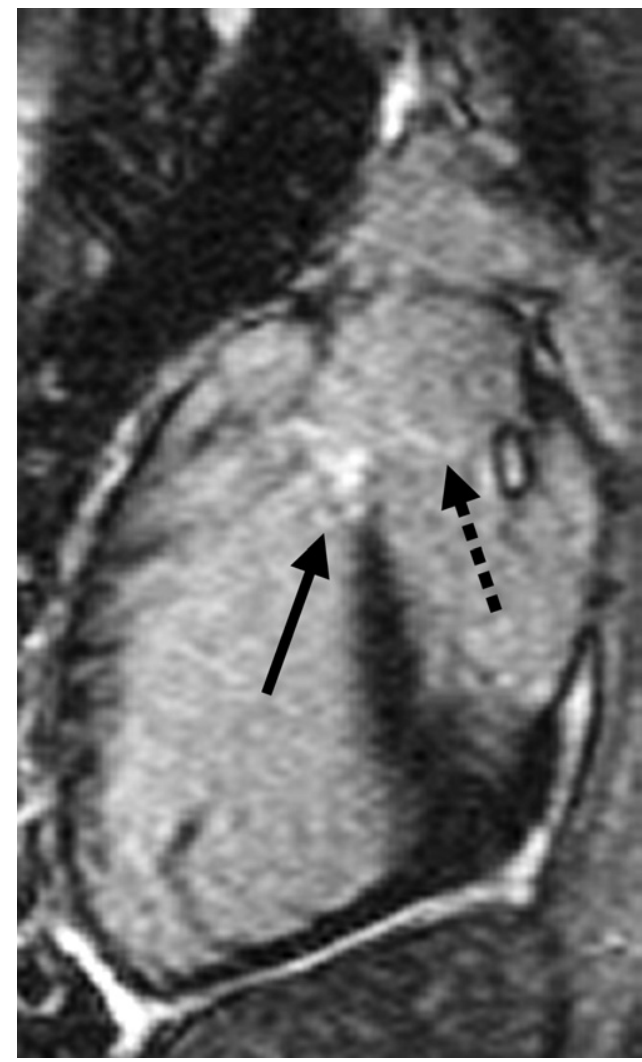

Figure 2. A 16-year-old boy after tetralogy of Fallot repair in infancy. Delayed enhancement of the aortic valve (dashed arrow) and ventricular septal defect patch (solid arrow) are observed. patients $(P<.001)$ (Figures 1 and 2; Table 4). Fifteen (79\%) of the 19 patients who underwent right ventriclepulmonary artery conduit placement had at least qualitatively moderate obstruction in the region of the DE. Of the 3 group A patients who did not have DE of the RVOT, only 1 had a conduit, and the conduit was unobstructed. In group A, the mean right ventricular ejection fraction was $61 \% \pm$ $9 \%$. The mean pulmonary regurgitant fraction was $30 \% \pm$ $16 \%$.

\section{Cardiac Valves}

DE of the aortic valve occurred in 13 of 34 group A patients versus 2 of 31 group B patients (38\% vs 7\%; $P=.002$ ) (Figures 2 and 3; Table 4). DE of the mitral valve occurred in $22(65.0 \%)$ of 34 group A patients and $14(42 \%)$ of 33 group B patients $(P=.088$ ) (Figures 1 and 3; Table 4). DE of the tricuspid valve occurred in $25(74 \%)$ of 34 group A patients versus 17 (52\%) of 33 group B patients $(P=.080)$ ( Figure 4B; Table 4).

In group $\mathrm{A}, \mathrm{DE}$ of the mitral $(22 / 34,65.0 \% ; P=.004)$ and tricuspid valves $(25 / 34,74 \% ; P=.03)$ occurred more frequently than DE of the aortic valve (13/34, 38\%). In group $\mathrm{B}, \mathrm{DE}$ of the mitral $(14 / 33,42 \% ; P=.001)$ and tricuspid valves $(17 / 33,51 \% ; P<.001)$ occurred more frequently than $\mathrm{DE}$ of the aortic valve $(2 / 33,7 \%)$. The pulmonary and conduit valves were rarely observed and therefore no comparison was possible.

\section{DE of the Ascending Aorta}

DE of the ascending aorta was observed in 10 (38\%) of 26 group A patients and 3 (13\%) of 24 group B patients $(P=$ .03) (Figure 3; Table 4). The ascending aorta was not observed in 8 group A patients and 9 group B patients. 

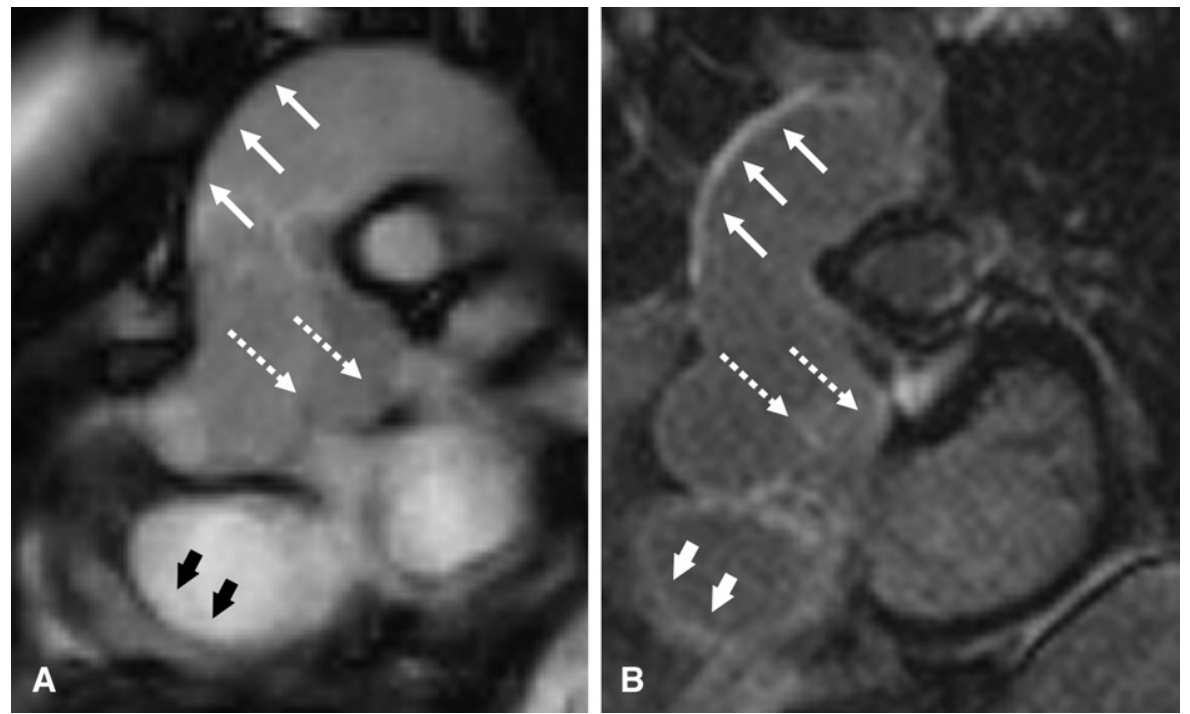

Figure 3. An 8-year-old girl after tetralogy of Fallot repair. A, Cine image of the ascending aorta (solid arrows), and the aortic (dashed arrows) and tricuspid (arrowheads) valves. B, Corresponding delayed enhancement image. Note the delayed enhancement of the ascending aorta, as well as the aortic and tricuspid valves. These structures exhibit delayed enhancement, even though they were not directly involved in the surgical reconstruction.

DE of Homograft Reconstruction of the Aorta Five (83\%) of 6 Norwood reconstructions compared with 3 (13\%) of 24 group B patients showed DE $(P=.002)$.

\section{Structurally Abnormal Valves}

In group A, 2 of the 5 patients with truncus arteriosus had DE of the truncal valve (Figure 1). In group B, there were 7 patients with bicuspid aortic valve. Of these, only $1(14 \%)$ exhibited DE of the aortic valve and the ascending aorta. The remaining 6 had no DE of either the aortic valve or the ascending aorta. In group $\mathrm{B}$, there was 1 patient with Ebstein anomaly who showed DE of the septal leaflet of the tricuspid valve (Figure E1, $A$, and E1, $B$ ).

\section{Discussion}

This cardiac MR study demonstrates that after intravenous administration of gadopentetate dimeglumine, DE is readily observed on homograft patches/conduits and VSD patches. This study extends the recent findings in adult TOF patients ${ }^{15,16}$ to the pediatric population. In addition, our findings of DE MR are validated through comparing them with an age-matched control population (group $\mathrm{B}, \mathrm{n}=33$ ) that never underwent cardiovascular surgery.

We studied younger patients to stress that fibrous tissue deposition is significant enough to image even among infants, children, and young adults. During these early postoperative years, patients generally do not exhibit right ventricular dysfunction from chronic valvular or conduit incompetence and the resultant volume overload. Our findings of frequent DE along RVOT reconstructions (31/34, $91 \%$ ) occur in the context of a preserved mean right ventricular ejection fraction $(61 \% \pm 9 \%)$. This is in contrast to the adult TOF patient studies, ${ }^{15,16}$ which reported signifi-
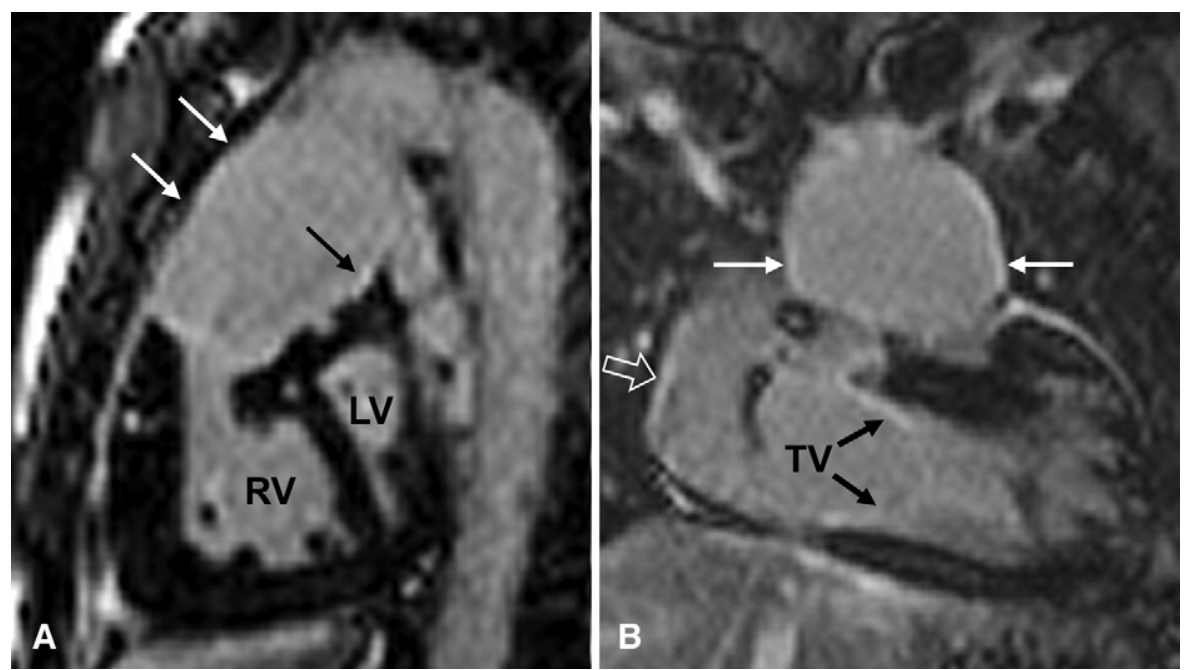

Figure 4. A 2-year-old patient after Norwood aortic reconstruction and Fontan operation for hypoplastic left heart syndrome. A, Note the delayed enhancement along the anterior (white arrows) and posterior walls (black arrows) of the Norwood reconstruction. $B$, Delayed enhancement confirmed in the coronal view. Interestingly, the tricuspid valve (black arrows) and the lateral wall of the lateral-tunnel Fontan (open arrows) also exhibit delayed enhancement. $L V$, Left ventricle; $R V$, right ventricle; $T V$, tricuspid valve. 
cantly lower right ventricular ejection fractions in the populations that had DE. The differences in right ventricular function between the two studies suggest that the impact of DE differs between the pediatric and adult populations.

Identifying fibrous material in the pediatric context may be important, because the fibrosis may contribute to RVOT obstruction in the form of a fibrous peel within a conduit. Nearly half of our surgically treated patients had at least qualitatively moderate-range conduit stenosis. Conduit obstruction is not an uncommon finding in the pediatric population because patients outgrow conduits placed in infancy.

It is unclear why DE of the RVOT homograft reconstruction was more common than DE of the artificial VSD patch (91\% vs $41 \%)$. It is possible that the original homograft collagenous skeleton provides the framework for fibrous tissue deposition through immune-mediated responses of the host to the donor tissue endothelial surface proteins, as has been postulated for cryopreserved homograft valve implant failure. ${ }^{7}$ Similar to RVOT homograft patch reconstructions, it is understandable that DE of Norwood homograft reconstructions is common when compared with normal aortas.

Interestingly, we observed that even structures not directly involved in the surgical repair may exhibit DE. For instance, patients with repaired conotruncal anomalies without homograft reconstruction of the ascending aorta exhibited $\mathrm{DE}$ of the ascending aorta more frequently than the control population (41\% vs $13 \% ; P=.05)$. DE of the aortic wall unrelated to surgical reconstruction has been reported in Takayasu arteritis, ${ }^{18}$ which is thought to result from aortic wall inflammation. Furthermore, DE of the aortic valve occurred more commonly in the group with repaired conotruncal anomalies than in the control group (37\% vs $6 \% ; P<.01)$. Dilation of the aortic root and ascending aorta frequently occurs in patients with TOF. Recently, the histologic basis of TOF aortopathy in infants and adults was described by Tan and associates. ${ }^{17}$ The findings included fibrosis, cystic medial necrosis, elastic fragmentation, and elastic lamellae disruption involving the aorta and the aortic sinuses. We speculate that these abnormal histologic findings could result in impaired gadolinium washout kinetics and provide a possible explanation for our observation of DE of aortas and aortic valve cusps in patients with conotruncal anomalies. Tan and colleagues ${ }^{17}$ also found earlier onset of elastin fragmentation and elastin lamellae disruption of the aortic root and ascending aorta in patients with TOF in contrast to those with a bicuspid aortic valve. Although not statistically significant, we found a trend among our pediatric study population showing that patients with repaired conotruncal anomalies exhibited DE of the aortic valve (14/34) and ascending aorta (10/26) more often than do patients with a bicuspid aortic valve (1/7). Nevertheless, it is possible that the fibrous tissue identified in the ascending aorta could be related to a previous cannulation site or aortic crossclamping. However, the degree of DE observed was diffuse and not discrete and, therefore, would less likely be thought to result from aortic cannulation or crossclamping. Finally, though it had not previously been reported, we are reassured that our findings of DE of valve tissue are valid, inasmuch as it is present on DE images performed at other institutions. ${ }^{19}$

Though metabolically active, cardiac valves have been thought to be relatively avascular structures, possessing few capillaries proximally, receiving their blood supply primarily via diffusion. ${ }^{20}$ Weind, Ellis, and Boughner ${ }^{21}$ demonstrated the existence of a more extensive vasculature than previously thought in the aortic valve of swine and suggested that cryopreserved homograft implants fail owing to the absence of this functioning vasculature. It is interesting that in our study atrioventricular valves exhibit DE more frequently than aortic valves, in both the repaired conotruncal and control groups. Though the reason for this finding is unclear, it suggests that different contrast washout kinetics operate between atrioventricular and semilunar valves. It is also interesting that the tricuspid valve was frequently enhanced in both the surgical and control groups ( $74 \%$ vs $52 \%$ ), without statistical difference. Inasmuch as the DE was not confined to the septal leaflet of the tricuspid valve, one can reasonably consider that tricuspid valve DE is a property of its contrast washout kinetics and not the result of VSD closure.

\section{Study Limitations}

Preoperative cardiac MR studies were not available in any of our patients with conotruncal anomalies (group A). These data would be useful in further confirming the presence and extent of DE associated with surgical reconstructions. In addition, preoperative MR studies might clarify whether the increased frequency of DE of the aortic valve and ascending aorta in patients with repaired conotruncal anomalies was a result of the native disease or, in part, related to the postoperative state.

\section{Conclusions}

In conclusion, DE MR imaging identifies fibrous tissue associated with surgical patch reconstructions in pediatric patients undergoing surgery for congenital heart disease. In addition, DE imaging also identifies fibrous structures not directly involved in the surgical repair, such as the ascending aortas of patients with conotruncal anomalies and in cardiac valves. We believe that this imaging technique will prove useful in the assessment of fibrous tissue formation associated with congenital heart disease and its evolving treatments. 


\section{References}

1. Castaneda AR, Jonas RA, Mayer JE Jr, Hanleya FL. Conduits: clinical and experimental aspects: In: Castaneda AR, Jonas RA, Mayer JE Jr, Hanley FL, editors. Cardiac surgery of the neonate and infant. Philadelphia: WB Saunders; 1994. p. 109-22.

2. Perryman RA, Jaquiss RD. Tetralogy of Fallot: In: Kaiser LR, Kron IL, Spray TL, editors. Mastery of cardiothoracic surgery. Philadelphia: Lippincott-Raven; 1998. p. 831-8.

3. Knott-Craig CJ. Ventricular septal defects: In: Kaiser LR, Kron IL, Spray TL, editors. Mastery of cardiothoracic surgery. Philadelphia: Lippincott-Raven; 1998. p. 687-96.

4. Herring M, Baughman S, Glover J, Kesler K, Jesseph J, Campbell J, et al. Endothelial seeding of Dacron and polytetrafluoroethylene grafts: the cellular events of healing. Surgery. 1984;96:745-55.

5. Herring M, Gardner A, Peigh P, Madison D, Baughman S, Brown J, et al. Patency in canine inferior vena cava grafting: effects of graft material, size, and endothelial seeding. J Vasc Surg. 1984;1:877-87.

6. Schoen FJ. Pathology of heart valve substitution with mechanical and tissue protheses: In: Silver MD, Gotlieb AI, Schoen, FJ, editors. Cardiovascular pathology. Philadelphia: Churchill Livingstone; 2001. p. 629-77.

7. Mitchell RN, Jonas RA, Schoen FJ. Pathology of explanted cryopreserved allograft heart valves: comparison with aortic valves from orthotopic heart transplants. J Thorac Cardiovasc Surg. 1998;115:118-27.

8. Kim RJ, Fieno DS, Parrish TB, Harris K, Chen EL, Simonetti O, et al. Relationship of MRI delayed contrast enhancement to irreversible injury, infarct age, and contractile function. Circulation. 1999;100: 1992-2002.

9. Simonetti OP, Kim RJ, Fieno DS, Hillenbrand HB, Wu E, Bundy JM, et al. An improved MR imaging technique for the visualisation of myocardial infarction. Radiology. 2001;218:215-23.

10. Shan K, Constantine G, Sivananthan M, Flamm S. Role of cardiac magnetic resonance imaging in the assessment of myocardial viability. Circulation. 2004;109:1328-34.

11. Moon JC, Reed E, Sheppard MN, Elkington AG, Ho SY, Burke M, et al. The histologic basis of late gadolinium enhancement cardiovas- cular magnetic resonance in hypertrophic cardiomyopathy. J Am Coll Cardiol. 2004;43:2260-4.

12. Rehwald WG, Fieno DS, Chen EL, Kim RJ, Judd RM. Myocardial magnetic resonance imaging contrast agent concentrations after reversible and non-reversible injury. Circulation. 2002;105:224-9.

13. Kim RJ, Chen E, Lima JA, Judd RM. Myocardial Gd-DTPA kinetics determine MRI contrast enhancement and reflect the extent and severity of myocardial injury after acute reperfused infarction. Circulation. 1996;94:3318-26.

14. Lima JA, Judd RM, Bazille A, Schulman SP, Atalar E, Zerhouni EA. Regional heterogeneity of human myocardial infarcts demonstrated by contrast-enhanced MRI: potential mechanisms. Circulation. 1995;92: 1117-25.

15. Oosterhof T, Mulder BMJ, Vliegen H, de Roos A. Corrected tetralogy of Fallot: delayed enhancement in right ventricular outflow tract. Radiology. 2005;237:868-71.

16. Babu-Narayan S, Kilner PJ, Li W, Moon JC, Goktekin O, Davlouros $\mathrm{PA}$, et al. Ventricular fibrosis suggested by cardiovascular magnetic resonance in adults with repaired tetralogy of Fallot and its relationship to adverse markers of clinical outcome. Circulation. 2006;113:405-13.

17. Tan JL, Davlouros PA, McCarthy KP, Gatzoulis MA, Ho SY. Intrinsic histological abnormalities of aortic root and ascending aorta in tetralogy of Fallot; evidence of causative mechanism for aortic dilatation and aortopathy. Circulation. 2005;112:961-8.

18. Desai MY, Stone JH, Foo TK, Hellmann DB, Lima JA, Bluemke DA. Delayed contrast-enhanced MRI of the aortic wall in Takayasu's arteritis: initial experience. Am J Radiol. 2005;184:1427-31.

19. Babu-Narayan SV, Goktekin O, Moon JC, Broberg CS, Pantely GA, Pennell DJ, et al. Late gadolinium enhancement cardiovascular magnetic resonance of the systemic right ventricle in adults with previous atrial redirection surgery for transposition of the great arteries. Circulation. 2005;111:2091-8.

20. Schoen FJ, Edwards WD. Valvular heart disease: general principles and stenosis. In: Silver MD, Gotleib AI, Schoen FJ, editors. Cardiovascular pathology. Philadelphia: Churchill Livingstone. 2001. p. 402-42.

21. Weind KL, Ellis CG, Boughner DR. The aortic valve blood supply. J Heart Valve Dis. 2000;9:1-7; discussion 7-8. 
TABLE E1. Group A patient characteristics and clinical data-after conotruncal surgery

\begin{tabular}{|c|c|c|}
\hline \multicolumn{3}{|l|}{ Group A characteristics } \\
\hline $\mathrm{n}$ & 34 & \\
\hline Male & 22 & $66 \%$ \\
\hline Age at MRI (y) & $10.6( \pm 5.2)$ & \\
\hline Age at operation (y) & $1.6( \pm 2.7)$ & \\
\hline $\begin{array}{l}\text { Time between operation and } \\
\text { MRI (y) }\end{array}$ & $8.9( \pm 5.5)$ & \\
\hline Conduit & 19 & $56 \%$ \\
\hline Transannular patch & 15 & $44 \%$ \\
\hline Ventricular septal defect patch & 34 & $100 \%$ \\
\hline Conduit stenosis & 15 & $\begin{array}{l}44 \% \text { (of total) } \\
79 \% \text { (of conduits) }\end{array}$ \\
\hline \multicolumn{3}{|l|}{ Type of congenital heart disease } \\
\hline Tetralogy of Fallot & 27 & $79 \%$ \\
\hline Truncus arteriosus & 5 & $15 \%$ \\
\hline $\begin{array}{l}\text { Transposition of the great } \\
\text { vessels }\end{array}$ & 1 & $3 \%$ \\
\hline Double-outlet right ventricle & 1 & $3 \%$ \\
\hline \multicolumn{3}{|l|}{ Physiology } \\
\hline $\begin{array}{l}\text { Right ventricular ejection } \\
\text { fraction }(\%)\end{array}$ & $61( \pm 9)$ & \\
\hline $\begin{array}{l}\text { Pulmonary regurgitant fraction } \\
(\%)\end{array}$ & $30( \pm 16)$ & \\
\hline
\end{tabular}

$M R I$, Magnetic resonance imaging.

TABLE E3. Group C patient characteristics and clinical data-after Norwood reconstruction

\begin{tabular}{lcr}
\hline Group C characteristics & \\
\hline$n$ & 6 & \\
Male & 3 & $50 \%$ \\
Age at MRI (y) & $7.9( \pm 7.4)$ & \\
Age at Norwood & $2-40$ days & $83 \%$ \\
HLHS & 5 & $17 \%$ \\
DILV & 1 & \\
\hline DILV, Double-inlet left ventricle; HLHS, hypoplastic left heart syndrome; \\
MRI, magnetic resonance imaging.
\end{tabular}


TABLE E2. Group B patient characteristics and clinical data-patients not treated surgically

Group B characteristics

\begin{tabular}{lcc}
\hline $\mathrm{n}$ & 33 & \\
Male & 19 & $58 \%$ \\
Age at MRI (y) & $11.5( \pm 6.7)$ & \\
Congenital heart disease & 15 & $46 \%$ \\
Acquired heart disease & 7 & $21 \%$ \\
No heart disease & 11 & $33 \%$
\end{tabular}

MRI, Magnetic resonance imaging.

TABLE E4. Delayed enhancement differences between groups

\begin{tabular}{|c|c|c|c|c|c|c|c|c|c|}
\hline \multirow[b]{2}{*}{ RVOT } & \multicolumn{3}{|c|}{$\begin{array}{c}\text { Group A }(n=34): \text { Conotruncal } \\
\text { anomaly }\end{array}$} & \multicolumn{3}{|c|}{ Group $B(n=33)$ : No surgery } & \multirow{2}{*}{$\begin{array}{c}\boldsymbol{P} \text { value } \\
<.01\end{array}$} & \multicolumn{2}{|c|}{ Group C $(n=6)$ : Norwood } \\
\hline & 31 & $91 \%$ & & 0 & & & & $\mathrm{n} / \mathrm{a}$ & \\
\hline VSD patch/LVOT & 14 & $41 \%$ & & 0 & & & $<.01$ & $\mathrm{n} / \mathrm{a}$ & \\
\hline Aortic valve & 13 & $38 \%$ & & 2 & $6 \%$ & & $<.01$ & $\mathrm{n} / \mathrm{a}$ & \\
\hline Tricuspid & 25 & $74 \%$ & & 17 & $52 \%$ & & .08 & $\mathrm{n} / \mathrm{a}$ & \\
\hline Mitral & 22 & $65 \%$ & & 14 & $42 \%$ & & .09 & $\mathrm{n} / \mathrm{a}$ & \\
\hline AAO/Norwood & 10 & $38 \%$ & $(n=26)^{*}$ & 3 & $13 \%$ & $(n=24)^{*}$ & .05 & $83 \%$ & $P<.01$ \\
\hline
\end{tabular}

$\overline{A A O}$, Ascending aorta; $L V O T$, left ventricular outflow tract; $n / a$, not available; RVOT, right ventricular outflow tract; VSD, ventricular septal defect. *Retrospective delayed enhancement assessment was not possible in 8 group A and 9 group B patients because the ascending aorta was not imaged.
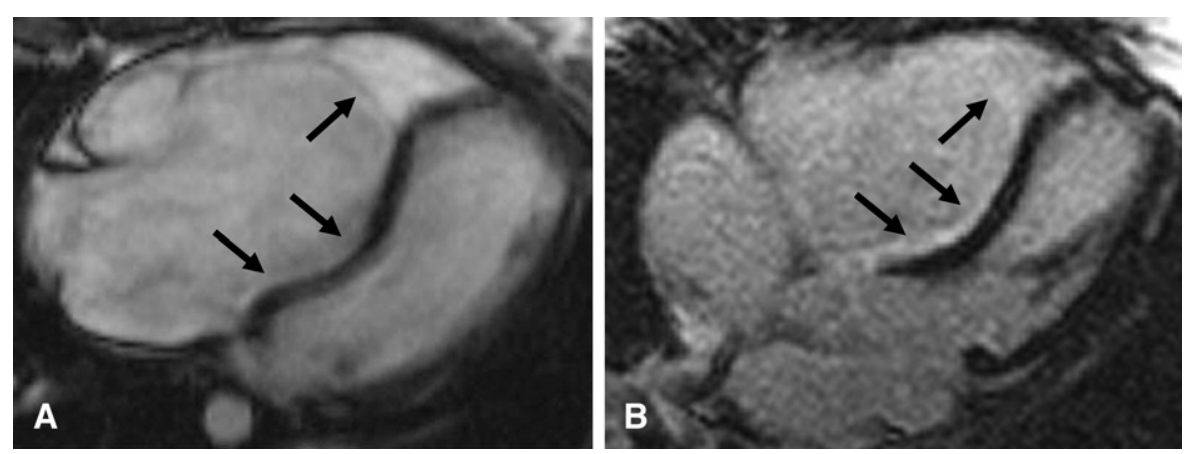

Figure E1. A 19-year-old patient born with Ebstein anomaly of the tricuspid valve. A, Cine image demonstrates the dilated atrialized portion of the right ventricle. Arrows point to the region where the rudimentary septal leaflet resides. $B$, The corresponding delayed enhancement image highlights the rudimentary septal leaflet. 